\title{
A Multi-task Principal Agent Model for Knowledge Contribution of Enterprise Staff
}

\author{
Cheng-yi Le \\ East China Jiaotong University, Nanchang, China
}

ncycy@126.com

\begin{abstract}
According to the different behavior characteristics of knowledge contribution of enterprise employees, a multi-task principal-agent relationship of knowledge contribution between enterprise and employees is established based on principal-agent theory, analyzing staff's knowledge contribution behavior of knowledge creation and knowledge participation. Based on this, a multi-task principal agent model for knowledge contribution of enterprise staff is developed to formulate the asymmetry of information in knowledge contribution Then, a set of incentive measures are derived from the theoretic model, aiming to prompt the knowledge contribution in enterprise. The result shows that staff's knowledge creation behavior and positive participation behavior can influence and further promote each other Enterprise should set up respective target levels of both knowledge creation contribution and knowledge participation contribution and make them irreplaceable to each other. This work contributes primarily to the development of the literature on knowledge management and principal-agent theory. In addition, the applicability of the findings will be improved by further empirical analysis.
\end{abstract}

Keywords: multi-task principal-agent model, knowledge contribution, knowledge creation and participation, Incentive measures

\section{Introduction}

Employees, both the creators and users of knowledge, are enterprises' key resources and sources of knowledge (Nonaka \& Konno, 1998). The construction and development of enterprise knowledge base relies on staff's collective participation and wisdom, and knowledge sharing and contribution are required to achieve and sustain competitive advantage (Pai \& Chang, 2013). However, employees worry that their knowledge dominance may be jeopardized, thus they have no willingness to share useful knowledge with others (Y-W Liu \& Phillips, 2011). It is worth mentioning that how to motivate staff to contribute knowledge has been a crucial issue in the research and practice of enterprise knowledge management (Hansen \& Avital, 2005; Le, Xu, Gu,

(CC BY-NC 4.0) This article is licensed to you under a Creative Commons Attribution-

NonCommercial 4.0 International License. When you copy and redistribute this paper in full or in part, you need to provide proper attribution to it to ensure that others can later locate this work (and to ensure that others do not accuse you of plagiarism). You may (and we encourage you to) adapt, remix, transform, and build upon the material for any non-commercial purposes. This license does not permit you to use this material for commercial purposes.
Pan, Dai, \& Peng, 2011).

Studies have shown that the largest challenge to knowledge management is whether individuals have intentions to propagate and share useful knowledge (Reychav \& Weisberg, 2010). Oyemomi, Liu, Neaga, and Alkhuraiji (2016) demonstrate the important role of organizational operation factors (leadership support, learning and training and communication) in knowledge sharing and businessknowledge process, which directly contribute to the 
improvement of organizational performance. And enterprise always will take some incentive measures according to their knowledge contribution behaviors, to encourage employees to share their knowledge. The principal-agent model (Mascolell, Whinston, \& Green, 1995) borrowed from economics is an appropriate framework to formulate the asymmetry of information in knowledge sharing. However, the simple model didn't consider the discrepancies of different knowledge contribution behaviors. Knowledge contribution represents the total contribution of enterprise knowledge dedicated by the staff, through knowledge creating, sharing, evaluating, and so on. It can be divided into knowledge creation contribution (by creating new knowledge) and knowledge participation contribution (by sharing and evaluating knowledge, etc.). Knowledge participation behavior and knowledge creation behavior have different effects on the knowledge contribution in enterprise (Le et al., 2011). Based on the multi-task principal-agent theory, when the agent is engaged in a number of tasks, the pincipal may not make correct inferences about the proper incentives for one task by studying only the attributes of that task alone, as other tasks will also affect his/her inferences. (Holmstrom \& Milgrom, 1991). It is very important to consider the differences of knowledge contribution behaviors and to make different incentive measures of knowledge creation task and knowledge participation task.

Therefore, this paper introduces the multi-task principal-agent model (Holmstrom \& Milgrom, 1991), and constructs the multi-task principal-agent model between enterprise and employees, based on the multi-task of knowledge creation contribution and knowledge participation contribution. The main purpose is to extend the knowledge management literature by exploring the model and propose some incentive measures to solve the incentive problem in knowledge contribution, encouraging staff to create and share knowledge. Besides, the multi-task principal-agent model developed by this study is a theoretic model, and the applicability of the results will be improved by further empirical analysis.

\section{Literature Review}

The principal-agent theory has widely been applied in the research of information asymmetry and incentive issues, and it can be used to study the incentive problems of knowledge sharing in enterprise. Many scholars have applied the principal-agent theory in the economics analysis of incentive mechanism of knowledge sharing among employees. For instance, Nan (2008) developed a principal-agent model to formulate the asymmetry of information in knowledge sharing, to explore effective incentive design that can address the information asymmetry in knowledge sharing processes and variability of the intangible nature of knowledge. Wei and Ju (2009) established a knowledge sharing incentive mechanism model, dividing company clients into either risk neutral or risk averse, and discussed their respective optimal incentive contract. Fan and Ju (2009) studied enterprises' internal knowledge sharing mechanism under the condition of incomplete information. Zhang and $\mathrm{Lu}$ (2011) analyzed the incentive mechanism of crowd sourcing based on the principal-agent theory and discussed how the enterprise should design the incentive mechanism. $\mathrm{Yu}$, Zhao and $\mathrm{Li}$ (2011) put forward compensation strategy for tacit knowledge sharing behavior, helping to achieve the flow, transformation, sharing and innovation of tacit knowledge. M-S Liu (2012) explored the relationship among knowledge incentive mechanisms, knowledge psychological ownership, and individual knowledge creation behavior. Andersson, Björkman, and Forsgren (2005) developed five hypotheses that are tested on a sample of 140 foreign owned subsidiaries located in Finland and China; the result indicated that MNC (multinational corporation) headquarters can indeed influence subsidiary local network embeddedness, which in turn enhances subsidiary knowledge creation. Gong and Zhang (2014) proposed an incentive mechanism to realize knowledge sharing for improving the effect of the inter-organizational knowledge sharing in cooperative $R \& D$. In addition, some researches focused on the studies of knowledge contribution in online communities. Jin, Li, Zhong, and Zhai (2015) explored why users continuously contribute knowledge to online social Q\&A communities. Cheng and Guo (2015) brought social interac- 
tion tie and membership esteem together as the mediating variables between knowledge contribution and social identity to construct an inductive route model; it showed that self-identity can form through an inductive route. Ye, Feng, and Choi (2015) showed that perceived community support and perceived leader support positively affect users' knowledge contribution.

Although many scholars have studied the knowledge sharing problem based on principal agent theory, most of the principal-agent models of knowledge sharing have not considered the discrepancies between different knowledge behaviors of enterprise staff. (For example, knowledge creation behavior takes staff a long time and effort from staff while knowledge participation behavior does not; and few people have the ability to create original knowledge, but most people could participate in reading, sharing, and commenting on the existing knowledge.) Past studies have also have neglected the interaction between different knowledge contribution behaviors and tasks. Thus the multi-task principal agent model of the knowledge contribution is proposed to improve knowledge sharing in enterprise.

The remainder of this paper is organized as follows: the next section describes the principal-agent relationship between enterprise and staff, and the behavior of knowledge creation and participation. Then, the paper gives the methodology of multi-task principal-agent model for knowledge contribution. Then, it presents the results, analysis, and discussion of the model. Finally, the author concludes this study and proposes some future work.

\section{Description of Knowledge Contribution Relationship and Behavior}

\section{Principal-Agent Relationship of Enterprise Knowledge Contribution}

There is a principal-agent relationship of knowledge contribution between the enterprise manager and staff. The enterprise manager, as the principal, knows that knowledge comes from the minds of all staff, and encourages the staff to contribute their knowledge. As the owner of the knowledge, the staff is the agent of knowledge contributing. When the enterprise manager requests the staff to contribute their knowledge, the principal-agent relationship of the knowledge contribution of the enterprise is established, as shown in Figure 1. In addition, there is information asymmetry between the manager and the staff; the staff has information superiority, but enterprise manager doesn't.

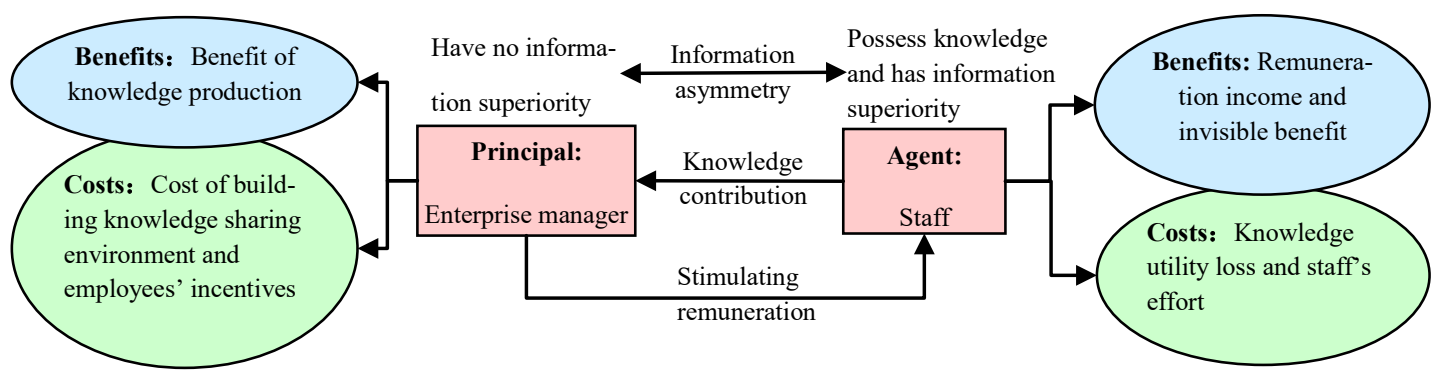

Figure 1. Principal-agent relationship of knowledge contribution between enterprise manager and staff.

The staff doesn't contribute their knowledge without stimulating remuneration. Then the enterprise manager provides some incentive to encourage the staff to contribute their own knowledge, aiming to maximize benefits of the enterprise. The staff considers that knowledge contribution will take a long time and efforts and will also lose their ownership of the knowledge. By weighing the benefits and costs of knowledge contribution, the staff determines the level of knowledge 
contribution. It is worth explaining that, the agent will also benefit by the knowledge shared by other agents. To simplify this relationship, it doesn't consider the influences between agents.

\section{Behaviors of Knowledge Creation and Knowledge Participation Contribution}

Knowledge contribution behaviors of the staff can be divided into two parts: direct knowledge contribution and indirect knowledge contribution. (1) Direct knowledge contribution: the staff produces and creates new knowledge to make contributions, such as new products, new design. (2) Indirect knowledge contribution: the staff takes an active part in knowledge sharing activities, e.g., knowledge reading, knowledge recommendation, knowledge transfer, knowledge evaluation, knowledge sharing, and exchanging (Le et al., 2011). Both of them are helpful for the positive knowledge sharing environment. The former, which requires much energy and time on knowledge creation and innovation, is called knowledge creation contribution behavior. The latter, which needs staff to actively participate in using, sharing, and evaluating enterprise knowledge, is called knowledge participation contribution behavior, as shown in Figure 2.

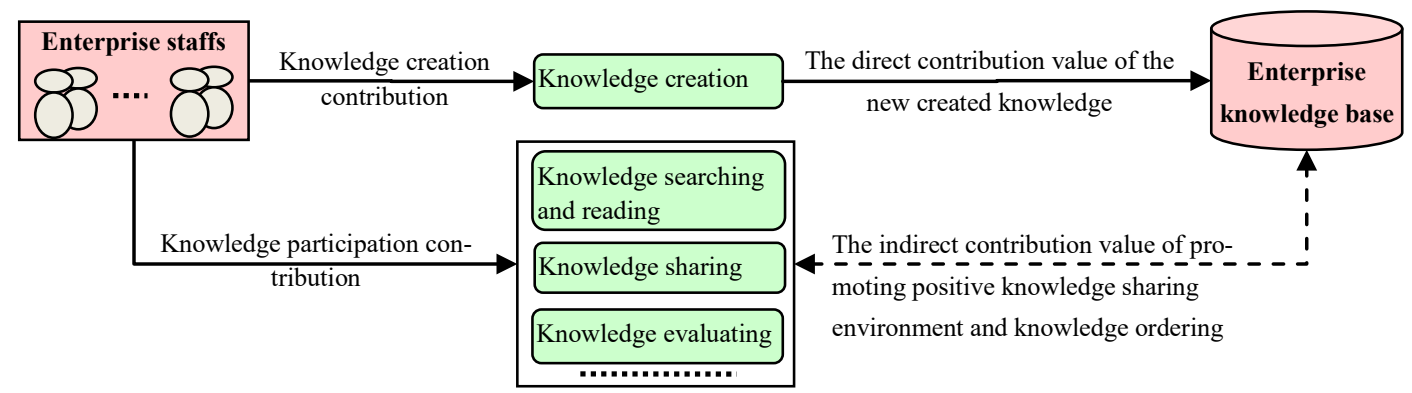

Figure 2: Behavior of knowledge creation and participation contribution.

\section{Methodology}

\section{Assumption and Function Description}

The paper makes the following assumptions about the Principal (enterprise manager, $\mathrm{P}$ ) and the Agent (employee, A). They are all independent people whose aim is to maximize their own interests. The risk attitude of the principal is risk neutral and the agent is risk aversion. There is information asymmetry between the principal and the agent, that is to say, the principal cannot fully understand the level of the efforts of knowledge contribution of the agent.

The agent has two knowledge contributing tasks: knowledge creation contribution and knowledge participation contribution. $a_{i}\left(a_{i} \geq 1, i=1,2\right)$ is used to express the efforts of the agent, and $a_{i}=1$ denotes that the level of staff effort is $0 ;{ }^{a}$ means the efforts that agent spent on knowledge creation, ${ }^{a_{2}}$ represents the agent's efforts of knowledge participation.

\section{(1) Knowledge production function}

According to the knowledge production function model proposed by Griliches (1979), the paper supposes that the agent's knowledge contribution output function is a linear function about the agent's effort level of knowledge contribution, so the knowledge contribution output function can be expressed as: $\pi_{i}=r_{i} a_{i}+\varepsilon_{i} . r_{i}$ is the coefficient of the agent's effort to output; ${ }^{\varepsilon_{i}}$ represents output random factors which obeys normal distribution, setting its mean to be 0 and covariance to 
be $\Sigma, i=1,2$ denotes the different results from different degrees of efforts of knowledge creation and knowledge participation.

$\pi_{1}=r_{1} a_{1}+\varepsilon_{1}, \pi_{2}=r_{2} a_{2}+\varepsilon_{2} ; \varepsilon_{1}, \varepsilon_{2}$ are respectively independent, and they are subject to normal distribution: $N=\left(0, \sigma_{1}^{2}\right)$. For simplicity, supposing if $r\left(a_{1}, a_{2}\right)=\left(a_{1}, a_{2}\right)$, so the output function is: $\pi_{i}=a_{i}+\varepsilon_{i} ; \pi_{i}$ as the expected revenue of the principal, is a strictly increasing convex function $\left(\frac{\partial \pi}{\partial a_{i}}>0, \frac{\partial^{2} \pi}{\partial a_{i}^{2}} \leq 0\right.$

\section{(2) Cost function of knowledge contributing}

The agent spends a certain amount of time and effort on knowledge creating, sorting, and sharing. So the paper assumes the effort cost function of the staff is $C=\frac{1}{2} c a^{2}, C\left(a_{1}, a_{2}\right)$ denotes the effort cost that the agent spends on knowledge creation and knowledge participation, and it is a strictly

increasing convex function (

$$
C_{i}=\frac{\partial C}{\partial a_{i}}>0, c_{i i}=\frac{\partial^{2} C}{\partial a_{i}{ }^{2}} \geq 0, c_{i j}=c_{j i} \text {. }
$$

- When $\mathrm{c}_{i j}=0$, it says that knowledge creation contribution and knowledge participation contribution of the agent are independent of each other, that is, a change of the effort cost of one task will not affect the effort cost of another task.

- When $c_{i j}<0, i \neq j$, it shows that the two tasks of the agent are mutually complementary, namely, the reduction of the effort cost of one task will cause the increase of the effort marginal cost of another task.

- When $c_{i j}>0, i \neq j$, it represents that two contribution tasks of the agent can be replaced, in other words, a rise in one task's effort cost will lead to an increase of another task's marginal effort cost.

\section{(3) Incentive contract function}

Since the principal cannot directly observe agent's effort level $\left({ }^{a_{i}}\right)$, but he can find agent's knowledge contribution output $\left(\pi_{i}\right)$, therefore, the incentive contract function is expressed as $s(\pi)=\alpha+\beta_{i} \pi_{i} ; \alpha$ is the fixed remuneration provided by the principal, $\beta_{i}$ as the incentive intensity of knowledge contribution.

\section{Multi-Task Principal-Agent Model for Knowledge Contributing of Enterprise Staff}

According to the above assumptions, the revenue of the principal depends on the effort the agent. The revenue can be calculated by subtracting the knowledge contribution contract payment from the agent's revenue expectation of knowledge output; the principal's expected revenue is:

$$
\begin{aligned}
& E\left(w_{p}\right)=E(\pi-s(\pi))=\pi\left(a_{1}, a_{2}\right)-\alpha-\beta^{T}\left(a_{1}, a_{2}\right) . \text { And the agent's expected revenue is: } \\
& E\left(w_{a}\right)=E(s(\pi)-C)=\alpha+\beta^{T}\left(a_{1}, a_{2}\right)-C\left(a_{1}, a_{2}\right) .
\end{aligned}
$$

Because the agent is risk averse, the risk cost of the external influence must be considered. Thus, the equivalence income of the agent is: 
$F_{a}=E\left[s(\pi)-C-\frac{1}{2} \rho \beta^{2} \sigma^{2}\right]=\alpha+\beta^{T}\left(a_{1}, a_{2}\right)-C\left(a_{1}, a_{2}\right)-\frac{1}{2} \rho \beta^{T} \Sigma \beta$, with $\rho$ being absolute risk aversion measure, $\Sigma$ being the covariance matrix of the random factor $\left(\varepsilon_{i}\right)$, and $\frac{1}{2} \rho \beta^{T} \Sigma \beta$ being the risk cost of the external influence of the agent.

The principal expects the agent to work hard for his own profit maximization, and the agent is also seeking for his own interests. So the incentive compatibility constraint (IC) is required, that is: $\max _{a} f_{a}=\alpha+\beta^{T}\left(a_{1}, a_{2}\right)-C\left(a_{1}, a_{2}\right)-\frac{1}{2} \rho \beta^{T} \Sigma \beta$.

The agents are willing to participate in knowledge contribution only if the profit is not less than the retained revenue. Therefore, the agent's participation constraint (IR) is necessary,

$$
F_{a}=\alpha+\beta^{T}\left(a_{1}, a_{2}\right)-C\left(a_{1}, a_{2}\right)-\frac{1}{2} \rho \beta^{T} \Sigma \beta \geq \omega, \omega \text { is the agent's retained revenue. }
$$

The problem that the principal faces is how to set $\beta^{T}$, so that his income $\left({ }^{F_{p}}\right)$ is the largest, as the function: $\max _{\beta^{T}} \max _{\beta^{T}} F_{p}=\pi\left(a_{1}, a_{2}\right)-\alpha-\beta^{T}\left(a_{1}, a_{2}\right)$.

By combining the constraints function of IC and IR with $\left({ }^{F_{p}}\right)$, the multi-task principal-agent knowledge contribution model can be built as:

$$
\begin{aligned}
& \max _{a_{i}, \beta^{T}} \max _{a_{i}, \beta^{T}} F_{p}=\pi\left(a_{1}, a_{2}\right)-\alpha-\beta^{T}\left(a_{1}, a_{2}\right) \\
& \text { s.t. }\left\{\begin{array}{l}
\max _{a} \max _{a} F_{a}=\alpha+\beta^{T}\left(a_{1}, a_{2}\right)-C\left(a_{1}, a_{2}\right)-\frac{1}{2} \rho \beta^{T} \Sigma \beta \\
\alpha+\beta^{T}\left(a_{1}, a_{2}\right)-C\left(a_{1}, a_{2}\right)-\frac{1}{2} \rho \beta^{T} \Sigma \beta \geq \omega
\end{array}\right.
\end{aligned}
$$

\section{Result Analysis and Discussion}

\section{Optimal Solution of the Principal-Agent Model}

According to the incentive compatibility constraint(IC), the agent gains the optimal revenue when $\frac{\partial F_{a}}{\partial a_{i}}=0$. Thus, $\frac{\partial \beta}{\partial a}=\left[\begin{array}{ll}\frac{\partial \beta_{1}}{\partial a_{1}} & \frac{\partial \beta_{1}}{\partial a_{2}} \\ \frac{\partial \beta_{2}}{\partial a_{1}} & \frac{\partial \beta_{2}}{\partial a_{2}}\end{array}\right]=\left[\begin{array}{ll}c_{11} & c_{12} \\ c_{21} & c_{22}\end{array}\right] \frac{\partial a}{\partial \beta}=\left[\begin{array}{ll}c_{11} & c_{12} \\ c_{21} & c_{22}\end{array}\right]^{-1}$; it denotes that the unit change of the agent's effort cost is equal to the sensitivity of the agent's effort level reacting to the incentive cost.

When the optimum condition as $\frac{\partial F_{p}}{\partial \beta}=0$, the total revenue of the principal is the largest by the participation constraints(IR); accordingly $\frac{\partial F_{p}}{\partial \beta}=\left(\frac{\partial \pi}{\partial a}\right)^{T}\left[c_{i j}\right]^{-1}-\beta^{T}\left[c_{i j}\right]^{-1}-\rho \beta^{T} \Sigma=0$, and $\beta=\left(I+\rho\left[c_{i j}\right] \Sigma \beta\right)^{-1} \frac{\partial \pi}{\partial a}$. 
As $\varepsilon_{1}$ and $\varepsilon_{2}$ are respectively independent, and covariance $(\Sigma)$ is a diagonal matrix, then $\beta=\left(I+\rho\left[c_{i j}\right] \sigma_{i}^{2}\right)^{-1} \frac{\partial \pi}{\partial a}$. In order to simplify the process, setting $\frac{\partial \pi}{\partial a}=\theta$, and the meaning of $\left(\theta_{1}, \theta_{2}\right)$ is the marginal revenue derived from the efforts spent on the two tasks. Thus, $\beta=\frac{\theta_{i}}{I+\rho\left[c_{i j}\right] \sigma_{i}^{2}}, \beta$ is a decreasing function of effort cost coefficient $(c)$, risk aversion $(\rho)$ and uncertain risk $(\sigma)$.

Because the knowledge participation contribution behavior of the agent can be recorded by using information measures, the principal can fully observe the degree of effort of knowledge participation contribution of agent, hence $\sigma_{2}^{2}=0$.

However, it is difficult to inspect the effort of knowledge creation contribution owing to the different knowledge levels of agents, and the inability of measuring tacit knowledge in their minds.

\section{Analysis and Discussion of the Model}

In light of the above analysis, it can be considered that there are three kinds of relationship between knowledge creation contribution and knowledge participation contribution, which are mutually independent, complementary and replaceable.

(1) When the knowledge creation contribution and knowledge participation contribution of the agent are independent of each other $\left(c_{i j}=0, i \neq j\right.$ ), which shows that the rising effort cost of one party would not cause the change of the cost of the other party.

$$
\left(\begin{array}{c}
\beta_{1} \\
\beta_{2}
\end{array}\right)=\left(\frac{\theta_{1}}{1+\rho c_{11} \sigma_{1}^{2}}\right)
$$

Due to the independence of two effort cost coefficients, the incentive coefficients ( $\beta_{i}$ ) of the two tasks are also independent. The incentive coefficient of knowledge creation contribution $\left({ }^{\beta_{1}}\right)$ is a decreasing function of effort cost coefficient $\left({ }^{c_{11}}\right)$, risk aversion $\left({ }^{\rho}\right)$ uncertain risk $\left({ }^{\sigma_{1}^{2}}\right)$, as shown in Figure 3.

The lower the risk aversion of the agent is, the higher the incentive intensity of knowledge creation should be given.

With the rising of marginal cost of knowledge creation, the principal should reduce the incentive intensity of it, while giving more incentives to knowledge participation contribution.

The principal should consider reducing the incentive intensity $\left(\beta_{1}\right)$ and giving more fixed remuneration $(\alpha)$ when the uncertain risk increases. 


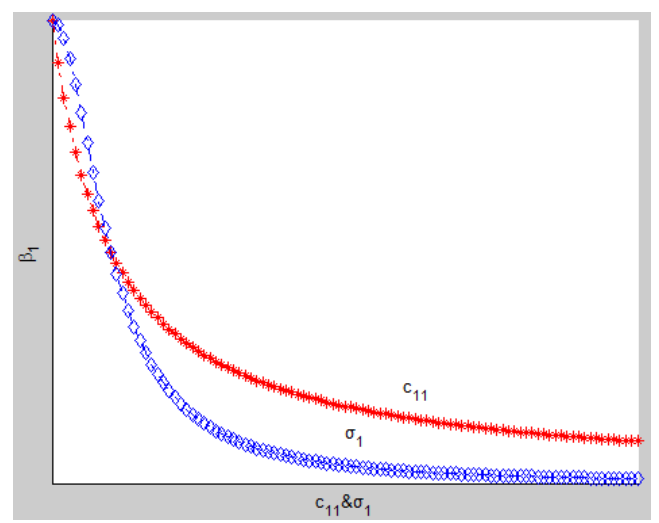

Figure 3.: The incentive coefficient of knowledge creation contribution ( $\left.{ }^{\beta_{1}}\right)$

$$
\text { changes with } c_{11} \text { or } \sigma_{1}^{2}
$$

(2) When the knowledge creation contribution and knowledge participation contribution of the agent are interdependent $\left(c_{i j} \neq 0\right.$ ), which demonstrates that change in one job's effort cost will lead to a change in the marginal cost of the other task.

$$
\left(\begin{array}{l}
\beta_{1} \\
\beta_{2}
\end{array}\right)=\left(\begin{array}{c}
\frac{\theta_{1}}{1+\rho c_{11} \sigma_{1}^{2}} \\
\theta_{2}-\frac{\rho c_{21} \sigma_{1}^{2}}{1+\rho c_{11} \sigma_{1}^{2}} \theta_{1}
\end{array}\right)
$$

The formula points $\beta_{1}$ has no relationship with $c_{i j}(i \neq j)$, namely, the incentive intensity of knowledge creation is independent of the relationship. The incentive intensity ( ${ }^{\beta_{1}}$ ) should be increased with the increase of the marginal revenue ${ }^{\theta_{1}}$, and be decreased with the increases of the risk aversion $(\rho)$, the effort cost of knowledge creation $\left({ }^{c_{11}}\right)$ and the uncertain factors $\left({ }^{\sigma_{1}^{2}}\right)$.

Besides, the discussion of incentive coefficients of knowledge participation contribution $\left(\beta_{2}\right)$ can be divided into two different cases.

- When the knowledge creation contribution and the knowledge participation contribution of the agent are complementary to each other $\left({ }^{c_{i j}<0, i \neq j}\right)$. Because $\mathrm{c}_{21}<0, \beta_{2}$ should be increased as the marginal cost of effort $\left({ }^{c_{21}}\right)$ and the marginal revenue of the knowledge creation $\left(\theta_{1}\right)$. Therefore, enterprises should increase incentive intensity of the knowledge creation and knowledge participation contribution, so that the overall knowledge contribution output of staff would be improved.

- When the knowledge creation contribution and the knowledge participation contribution of the agent can be replaced with each other $\left({ }^{c_{i j}}>0, i \neq j\right)$. As $c_{21}>0, \beta_{2}$ should be decreased with the increase of the marginal cost $\left({ }^{c_{21}}\right)$; that is to say, when knowledge creation contribution can be replaced by knowledge participation contribution, enterprises should reduce the incentive intensity of knowledge participation contribution. Employees will participate in the knowledge participation for getting a higher knowledge contribution output if $\beta_{2}$ is comparatively high, while ignoring the contribution of knowledge creation. Consequently, enter- 
prises should reduce ${ }^{\beta_{2}}$, prompting the staff to contribute knowledge creation, as shown in Figure 4.

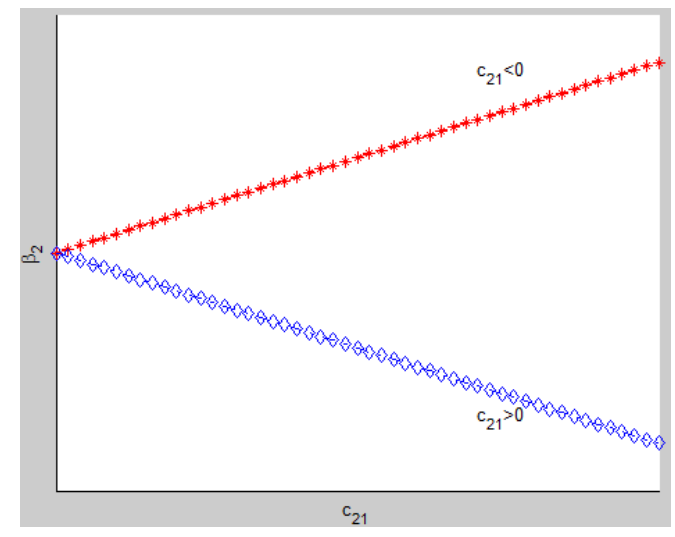

Figure 4. The incentive coefficient of knowledge participation contribution ( ${ }^{\beta_{2}}$ ) changes with $c_{21}$.

After all, when knowledge creation and knowledge participation are interdependent, incentive of knowledge creation contribution has nothing to do with the relationship between them, but the incentive intensity of knowledge participation contribution is associated with the relation between the two.

\section{Conclusions}

In this paper, a multi-task principal agent model is built to analyze the incentive measures of knowledge contribution. The principal-agency theory and mechanism design theory is applied by considering the multi-task of knowledge creation and participation. The main results are as follows:

(1) In general, the two tasks of knowledge creation and participation are mutually interdependent. Staff's knowledge creation behavior and positive participation behavior play a mutual promoting role in advancement of enterprise knowledge. For example, knowledge created by an employee is not valuable until other employees read, evaluate, and use it; and the knowledge in enterprise will not be updated and enlarged without the creation of new knowledge.

(2) What is more, the effort cost coefficient $\left(c_{i j}>0, i \neq j\right)$ is more common in many cases; knowledge creation contribution and knowledge participation contribution are replaceable with each other. Under the circumstances, if the enterprise's incentive intensity of the knowledge participation is set too high, employees will focus on the participation and usage of the enterprise knowledge base, while ignoring the creation of new knowledge, which will cause lack of new creative knowledge in enterprise. The effective way to solve this problem is transforming the substitution relationship between the two tasks into complementary relationship $\left(c_{i j}<0, i \neq j\right.$ ). Therefore, enterprises should set up respective target levels of both knowledge creation contribution and knowledge participation contribution, making them irreplaceable to each other.

This study is one of the few that have explicitly analyzed the different effects of knowledge creation and knowledge participation, and studied the multi-task principal model for knowledge contribution. Although the analytical solutions from the stylized multi-task principal model still needs empirical validation, this study gives some incentive solution and offers an analytical 
framework that may help enterprises to design different incentive intensities for knowledge creation contribution and participation contribution.

In further studies, an enterprise knowledge community will be taken as an example, in which different incentives will be set for knowledge creation and participation tasks and empirical studies will be conducted to test how the incentives influence user's knowledge behavior.

\section{Acknowledgements}

This work is supported by National Natural Science Foundation of China(Grant Nos. 71301068), supported by a grant from the National High Technology Research and Development Program of China (863Program)(No.2013AA040602), Key Project in Jiangxi Education Science Program during the Twelfth Five-year Plan Period(No.15ZD3L018), Soft Science Research Program of Jiangxi Province(20161BBA10067), Postdoctoral Science Foundation of Jiangxi Province(NO.2015KY52), The Humanities and Social Sciences Plan of Jiangxi Province (No.GL1514).

\section{References}

Andersson, U., Björkman, I., \& Forsgren, M. (2005). Managing subsidiary knowledge creation: The effect of control mechanisms on subsidiary local embeddedness. International Business Review, 14(5), 521538.

Cheng, Z-C., \& Guo T-C. (2015).The formation of social identity and self-identity based on knowledge contribution in virtual communities: An inductive route model. Computers in Human Behavior, 43(2), 229-241.

Fan, B., \& Ju, X-F.. (2009). A research on incentive mechanism of knowledge sharing under incomplete information. Studies in Science of Science, 27(9), 1365-1369.

Griliches, Z. (1979). Issues in assessing the contribution of research and development to productivity growth. The Bell Journal of Economics, 10(1), 92-116.

Gong, L., \& Zhang, X-D.. (2014). Study of the game theory analysis and incentive mechanism of interorganizational knowledge sharing in cooperative R\&D. IERI Procedia, 10, 266-273.

Hansen, S., \& Avital, M. (2005). Share and share alike: The social and technological influences on knowledge sharing behavior. Systems and Organizations, 5(1), 1-19.

Holmstrom, B., \& Milgrom, P. (1991). Multitask principal-agent analyses: Incentive contracts, asset ownership and job design. Journal of Law, Economics \& Organization, 7(9), 24-52.

Jin, J-H., Li, Y-J., Zhong, X-J., \& Zhai, L. (2015). Why users contribute knowledge to online communities: An empirical study of an online social Q\&A community. Information \& Management, 52(7), 840-849.

Le, C-Y., Xu, F-Y., Gu, X-J., Pan, K., Dai, F., \& Peng, B-H. (2011). Evaluation model and algorithm for knowledge contribution of enterprise staff. Computer Integrated Manufacturing Systems, 17(3), 662671.

Liu, M-S. (2012). Impact of knowledge incentive mechanisms on individual knowledge creation behavior-An empirical study for Taiwanese R\&D professionals. International Journal of Information Management, 30(5), 442-450.

Liu, Y-W., \& Phillips, J. S.. (2011). Examining the antecedents of knowledge sharing in facilitating team innovativeness from a multilevel perspective. International Journal of Information Management, $31(1), 44-52$.

Mascolell, A., Whinston, M. D., \& Green, J. R. (1995). Microeconomic theory. Oup Catalogue, 44(4), 370372. 
Nan, N. (2008). A principal-agent model for incentive design in knowledge sharing. Journal of Knowledge Management, 12(3), 101-113.

Nonaka, I., \& Konno, N. (1998). The concept of 'Ba': Building a foundation for knowledge creation. California Management Review, 40(3), 40-55.

Oyemomi, O., Liu, S-F., Neaga, I., \& Alkhuraiji, A. (2016). How knowledge sharing and business process contribute to organizational performance: Using the fsQCA approach. Journal of Business Research, 69(11), 5222-5227.

Pai, F-Y., \& Chang, H-F. (2013). The effects of knowledge sharing and absorption on organizational innovation performance - A dynamic capabilities perspective. Interdisciplinary Journal of Information, Knowledge, and Management, 8, 83-97. Retrieved from http://www.informingscience.org/Publications/1904

Reychav, I., \& Weisberg, J. (2010). Bridging intention and behavior of knowledge sharing. Journal of Knowledge Management, 14(2), 285-300.

Wei, H-M., \& Ju, X-F. (2009). Research on incentive mechanism of knowledge sharing of enterprise - type customer based on principal-agent theory. Chinese Journal of Management Science, 19(10), 478-484.

Ye, H. J., Feng, Y, F., \& Choi, B. C. F. (2015). Understanding knowledge contribution in online knowledge communities: A model of community support and forum leader support. Electronic Commerce Research and Applications, 14(1), 34-45.

Yu, L., Zhao, S-J., \& Li, Z. (2011). Studies on the incentive mechanism of TMT tacit knowledge sharing behavior: Analysis based on multi-task principal-agent model. Science-Technology and Management, 13(3), 44-47.

Zhang, P., \& Lu, R-Y. (2011). On incentive mechanism of crowdsourcing innovation --By principal-agent theory. Technoeconomics \& Management Research, 6, 45-48.

\section{Biography}

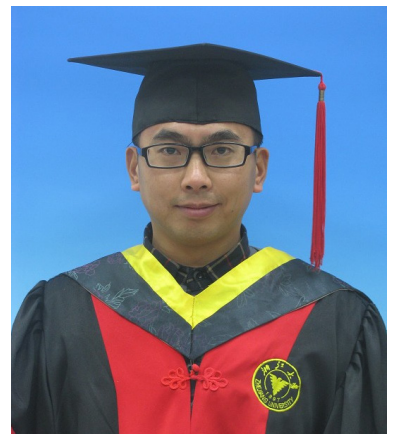

Cheng-yi Le is Associate Professor of School of Economic and Management at East China Jiaotong University (Nanchang, China), and he received his $\mathrm{PhD}$ degree in Industrial Engineering from ZheJiang University (Hangzhou, China) in 2013. Dr. Le's research interests include knowledge management and data mining. He has published articles in Enterprise Information Systems, Computer Integrated Manufacturing Systems. His current work focuses on knowledge sharing and collective wisdom on the internet. 